\title{
Topics in acute respiratory distress syndrome: the patient needs our tender loving and care
}

\author{
S. John Wort ${ }^{1,2}$, Laura Price ${ }^{1,2}$ and Stefano Nava ${ }^{3}$
}

\begin{abstract}
Affiliations: 'Dept of Critical Care and Pulmonary Hypertension, Royal Brompton Hospital, London, UK. ${ }^{2}$ Section of Vascular Biology, National Heart and Lung Institute, Imperial College, London, UK. ${ }^{3}$ Respiratory and Critical Care, Sant'Orsola Malpighi Hospital, Alma Mater Studiorum, University of Bologna, Dept of Specialist, Diagnostic and Experimental Medicine (DIMES), Bologna, Italy.
\end{abstract}

Correspondence: S. John Wort, Dept of Critical Care and Pulmonary Hypertension, Royal Brompton Hospital, Sydney Street, London, SW3 6NP, UK. E-mail: s.wort@imperial.ac.uk

@ERSpublications

This editorial introduces a new series on acute respiratory distress syndrome summarising important clinical studies http://ow.ly/vDomD

This editorial introduces a four-part series on acute respiratory distress syndrome (ARDS) that will cover a wide range of related topics in reviews written by internationally renowned experts. The first part of this series will be published in this issue of the European Respiratory Review by GuérIN [1] on the role of prone positioning. This will be followed by articles on the topics of: 1) the role of imaging in the diagnosis and management of ARDS; 2) the novel ventilatory aspects involved in managing patients with ARDS; and 3) how to manage a patient failing conventional ventilation with extracorporeal support, in particular, extracorporeal membrane oxygenation (ECMO).

It is nearly 50 years since the first report of "acute respiratory distress in adults" by AsHBAUGH et al. [2]. This later became known as ARDS and acute lung injury (ALI). This group of conditions was characterised by acute onset of hypoxaemia associated with the presence of bilateral infiltrates on chest radiography, poor lung compliance and the exclusion of cardiogenic pulmonary oedema [3]. ARDS may develop after a diverse spectrum of causes. These associated conditions may be categorised according to the nature of the insult with, for example, pulmonary sepsis causing a "direct" insult whilst pancreatitis and non-pulmonary sepsis cause an "indirect" insult resulting in ARDS often as part of multi-organ dysfunction syndrome. Despite some evidence of improvements in mortality in selected centres over recent decades, ARDS remains a major public health problem with a 28-day mortality in the region of $25-35 \%$, and a corresponding large fiscal burden to national health services [4].

In 1994, an American-European Consensus Conference (AECC) formalised the criteria for the diagnosis of ARDS and ALI. Thus, ARDS was defined by an arterial oxygen tension $\left(\mathrm{PaO}_{2}\right) /$ inspiratory oxygen fraction $\left(\mathrm{FIO}_{2}\right)$ ratio of $<150$ and $\mathrm{ALI}$, at the milder end of the spectrum, as a $\mathrm{PaO}_{2} / \mathrm{FIO}_{2}$ ratio of $<300$ [5]. The definition of noncardiogenic pulmonary oedema was confirmed by a pulmonary artery wedge pressure of $<18 \mathrm{mmHg}$, necessitating the use of a Swan-Ganz catheter to make the formal definition. Although that definition is simple to apply in the clinical setting, it has been challenged over the years. For instance, it makes no sense that ALI could theoretically include all patients with a $\mathrm{PaO}_{2} / \mathrm{FiO}_{2}<300$. It also makes no attempt to prognosticate in terms of severity of injury. Also, it does not take into account the effect of ventilatory support. In 2011, in an attempt to address these issues and others, experts from Europe and the

Received: April 082014 | Accepted: April 082014

Conflict of interest: None declared.

Provenance: Submitted article, peer reviewed.

Copyright OERS 2014. ERR articles are open access and distributed under the terms of the Creative Commons Attribution Non-Commercial Licence 4.0. 
USA (an initiative of the European Society of Intensive Care Medicine endorsed by the American Thoracic Society and the Society of Critical Care Medicine) developed the Berlin Definition of ARDS [6]. This definition proposed three mutually exclusive categories of ARDS based on hypoxaemia, i.e. $\mathrm{mild}_{(\mathrm{PaO}} / \mathrm{FIO}_{2}$ $<300$ and $>200)$, moderate $\left(\mathrm{PaO}_{2} / \mathrm{FIO}_{2}<200\right.$ and $\left.>100\right)$ and severe $\left(\mathrm{PaO}_{2} / \mathrm{FIO}_{2}<100\right)$. The term ALI was dropped and replaced by a necessary ventilator parameter requirement of continuous positive airway pressure or positive end-expiratory pressure (PEEP) $>5 \mathrm{cmH}_{2} \mathrm{O}$. Using patient data from four multicentre clinical datasets (4188 patients) the Berlin Definition outperformed the earlier AECC definition in terms of predictive validity for mortality [6], although it should be stated that the receiver operating characteristic values still had scope for improvement. In subsequent studies, the Berlin Definition also correlated well to the amount of extravascular lung water and vascular permeability, and the presence of diffuse alveolar damage on histological analysis [7]. However, there is still scope for improvement. For instance, there is a need to consider that the $\mathrm{PaO}_{2} / \mathrm{FIO}_{2}$ may increase when $\mathrm{FIO}_{2}$ is raised from moderate to high levels, suggesting that patients with similar $\mathrm{PaO}_{2} / \mathrm{FIO}_{2}$ ratios, but different $\mathrm{FIO}_{2}$ levels, have different risks of mortality [8]. Indeed, those patients with raised transpulmonary gradient and right ventricular dysfunction, although outcomes are better in the era of protective ventilation [9], may still have a worse prognosis [10]. There is also a need to consider in more detail the type of ventilatory support and inclusion of a prognostic index, such as the Acute Physiology and Chronic Health Evaluation, Simplified Acute Physiology Score or Sequential Organ Failure Assessment scores. We await the impact of this new definition on outcomes in patients with ARDS.

Since the first description by Ashbaugh et al. [2], we certainly know more about the pathogenesis and pathophysiology of ARDS. Direct or indirect insults result in neutrophil- and platelet-dependent dysfunction of the alveolar-epithelial barrier. The resultant protein-rich pulmonary oedema fluid floods alveoli and causes surfactant dysfunction, which results in collapse and consolidation of lung units. Severe refractory hypoxaemia results from ventilation/perfusion mismatch due to impairment of hypoxic pulmonary vasoconstriction. In addition to hypoxaemia, hypercapnia is also a key feature of ARDS. This reflects involvement of the pulmonary microcirculation, due to both the disease process itself, as well as relating to the effects of positive pressure ventilation. Involvement of the pulmonary microcirculation is also important early in ARDS. For example, the inability to excrete carbon dioxide in those areas of lung being ventilated but not perfused, which equates to ventilatory dead space, can be measured at the bedside and is associated with mortality [11].

However, probably the most important advance in the management of patients with ARDS is the better understanding of ventilator-induced lung injury (VILI) and the subsequent increased use of protective lung strategies. Apart from the long recognised barotrauma, as a result of very high transpulmonary pressures, we now know that mechanical ventilation can damage the lungs in several additional ways: 1) volutrauma is overdistension of the lung associated with increased alveolar-capillary permeability; 2) atelectrauma is caused by cyclical opening and closing of lung units; and 3) biotrauma is a result of inflammatory mediators released by the inflamed lung, perpetuating the inflammatory process. Indeed mechanical ventilation can lead to epithelial cell apoptosis in the kidney and small intestine, accompanied by biochemical evidence of organ dysfunction. This may partially explain the high rate of multiple organ dysfunction syndrome observed in patients with ARDS. In 2000, ARDSnet, a network of research funded by the US National Heart, Lung and Blood Institute of the National Institutes of Health, published their first landmark paper [12]. This study demonstrated a $22 \%$ reduction in mortality in patients ventilated at $6 \mathrm{~mL} \cdot \mathrm{kg}^{-1}$ tidal volume versus $12 \mathrm{~mL} \cdot \mathrm{kg}^{-1}$ in the "conventional" group [12]. Moreover, ventilation at lower tidal volumes has been associated with a lower release of interleukin-6 [13], a cytokine implicated in the inflammatory process underpinning the progression of ARDS. Ventilation at $6 \mathrm{~mL} \cdot \mathrm{kg}^{-1}$ or even less has now become the gold standard. Interestingly, a follow-up study from the same network found no difference in mortality in patients treated with high PEEP (average $13.2 \mathrm{cmH}_{2} \mathrm{O}$ on days $1-4$ of ventilation) versus low PEEP (average $8.3 \mathrm{cmH}_{2} \mathrm{O}$ over the same time period) [14]. This result was unexpected as previous studies had shown higher PEEP was protective. Moreover, BRIEL et al. [15] demonstrated that protocolised ventilation designed to recruit and open the lung resulted in no significant difference in all-cause hospital mortality compared to the "classical" low tidal volume ventilation. However, there have been many arguments as to why these trials were negative, including the obvious one that the optimal PEEP is difficult to titrate. This has been suggested by Terragni et al. [16], who showed that limiting tidal volume to $6 \mathrm{~mL} \cdot \mathrm{kg}^{-1}$ predicted body weight and plateau pressure to $30 \mathrm{cmH}_{2} \mathrm{O}$ may not be sufficient in patients characterised by a larger nonaerated compartment. For this reason it has been postulated that the use of ventilatory settings guided by the oesophageal pressure may improve the oxygenation and compliance of the patients [17]. An extensive clinical review on this topic has been previously published [18].

Recently, another study has reported an apparently large impact on outcome in patients with ARDS and has changed clinical practice. GUÉRIN et al. [19] published the results of a large trial investigating the effect of 
prone positioning (versus supine) on mortality in patients with ARDS (PROSEVA; Proning Severe ARDS Study). In patients with severe ARDS, defined as a $\mathrm{PaO}_{2} / \mathrm{FIO}_{2}<150$, an $\mathrm{FIO}_{2}>0.6$ and PEEP $\geqslant 5 \mathrm{cmH}_{2} \mathrm{O}$, early application of prolonged proning sessions $\left(16 \mathrm{~h} \cdot \mathrm{day}^{-1}\right.$ started after a 24 -h stabilisation period) resulted in a significant reduction in 28- and 90-day mortality [19]. All patients were ventilated at a tidal volume of $6 \mathrm{~mL} \cdot \mathrm{kg}^{-1}$. The results were consistent with previous meta-analyses indicating a survival advantage, but are at odds with previous randomised trials that failed to show a survival benefit. There were few complications, but the authors did point out that the studies were performed in centres with experience in this manoeuvre. The success of this trial was probably due to a combination of factors, including the prolonged periods of proning, the period of stabilisation allowing for the most severe patients to be enrolled, and compliance with a strict low tidal volume strategy with limited peak plateau pressure. The benefit of proning itself is likely to involve a reduction in alveolar overdistension whilst enhancing alveolar recruitment, with a consequent improvement in oxygenation and reduction in VILI. One obvious question is how patient selection in the future fits into the new Berlin Definition of ARDS given that the patients recruited into PROSEVA did not fit neatly into the new severity categories.

The final area to mention in this overview of the history of ARDS is the coming of age of extracorporeal life support and, in particular, ECMO. In 2009, the CESAR (Conventional Ventilator Support versus Extracorporeal Membrane Oxygenation for Severe Adult Respiratory Failure) study proved that ECMO was safe, efficacious and cost-effective compared to "standard ventilation" [20]. In this study 180 patients with ARDS and a Murray Score of $>3$ were randomised to receive conventional ventilation or referral to a specialist ECMO centre (Glenfield Hospital, Leicester, UK) for consideration of ECMO. There was a significant reduction in mortality and severe disability in the ECMO group compared to those patients receiving conventional ventilation. There was criticism of the study design in that only $\sim 75 \%$ of the referred patients were put on ECMO after a re-evaluation of their severity. In addition, not all patients in the conventional group were ventilated in an ideal protective manner (only $30 \%$ had low tidal volumes). Despite this, ECMO was pushed into the public eye as the saviour of many patients affected by the severe seasonal influenza epidemics that emerged around the time of the study. As a result of this, ECMO is now a designated service in the UK and many other countries worldwide.

We have concentrated on the positive aspects of care for patients with ARDS and this new series will highlight and expand on many of them. However, it would give an unbalanced view if we did not mention that many well-performed studies have failed to show any survival benefit of disease modifying agents, such as surfactant therapy [21], activated protein C [22], inhaled nitric oxide [23] and, more recently, $\beta$-agonists [24] and neutrophil elastase inhibitors [25] amongst others in ongoing studies. Several ongoing trials are on the horizon [26]. There is also further work to be done to clarify the risk stratification of patients with ARDS. In addition, it is important to further consider the pathophysiology involved in right ventricular dysfunction, either as a result of the processes underlying ARDS itself or as a consequence of our ventilatory and non-ventilatory strategies.

\section{References}

Guérin C. Prone ventilation in acute respiratory distress syndrome. Eur Respir Rev 2014; 23: 249-257. Ashbaugh DG, Bigelow DB, Petty TL, et al. Acute respiratory distress in adults. Lancet 1967; 2: 319-323. Ware LB, Matthay MA. The acute respiratory distress syndrome. N Engl J Med 2000; 342: 1334-1349. McIntyre RC Jr, Pulido EJ, Bensard DD, et al. Thirty years of clinical trials in acute respiratory distress syndrome. Crit Care Med 2000; 28: 3314-3331.

5 Bernard GR, Artigas A, Brigham KL, et al. Report of the American-European consensus conference on acute respiratory distress syndrome: definitions, mechanisms, relevant outcomes, and clinical trial coordination. Consensus Committee. Am J Respir Crit Care Med 1994; 149: 818-824.

6 Ranieri VM, Rubenfeld GD, Thompson BT, et al. Acute respiratory distress syndrome: the Berlin Definition. JAMA 2012; 307: 2526-2533.

7 Thille AW, Esteban A, Fernandez-Segoviano P, et al. Comparison of the Berlin definition for acute respiratory distress syndrome with autopsy. Am J Respir Crit Care Med 2013; 187: 761-767.

8 Britos M, Smoot E, Liu KD, et al. The value of PEEP and $\mathrm{FIO}_{2}$ criteria in the definition of the acute respiratory distress syndrome. Crit Care Med 2011; 39: 2025-2030.

9 Jardin F, Fellahi JL, Beauchet A, et al. Improved prognosis of acute respiratory distress syndrome 15 years on. Intensive Care Med 1999; 25: 936-941.

10 Bull TM, Clark B, McFann K, et al. Pulmonary vascular dysfunction is associated with poor outcomes in patients with acute lung injury. Am J Respir Crit Care Med 2010; 182: 1123-1128.

11 Nuckton TJ, Alonso JA, Kallet RH, et al. Pulmonary dead-space fraction as a risk factor for death in the acute respiratory distress syndrome. $N$ Engl J Med 2002; 346: 1281-1286.

12 Ventilation with lower tidal volumes as compared with traditional tidal volumes for acute lung injury and the acute respiratory distress syndrome. The Acute Respiratory Distress Syndrome Network. N Engl J Med 2000; 342: $1301-1308$.

13 Parsons PE, Eisner MD, Thompson BT, et al. Lower tidal volume ventilation and plasma cytokine markers of inflammation in patients with acute lung injury. Crit Care Med 2005; 33: 1-6. 
14 Brower RG, Lanken PN, MacIntyre N, et al. Higher versus lower positive end-expiratory pressures in patients with the acute respiratory distress syndrome. N Engl J Med 2004; 351: 327-336.

15 Briel M, Meade M, Mercat A, et al. Higher vs lower positive end-expiratory pressure in patients with acute lung injury and acute respiratory distress syndrome: systematic review and meta-analysis. JAMA 2010; 303: 865-873.

16 Terragni PP, Rosboch G, Tealdi A, et al. Tidal hyperinflation during low tidal volume ventilation in acute respiratory distress syndrome. Am J Respir Crit Care Med 2007; 175: 160-166.

17 Talmor D, Sarge T, Malhotra A, et al. Mechanical ventilation guided by esophageal pressure in acute lung injury. N Engl J Med 2008; 359: 2095-2104.

18 Akoumianaki E, Maggiore SM, Valenza F, et al. The application of esophageal pressure measurement in patients with respiratory failure. Am J Respir Crit Care Med 2014; 189: 520-531.

19 Guerin C, Reignier J, Richard JC, et al. Prone positioning in severe acute respiratory distress syndrome. N Engl J Med 2013; 368: 2159-2168.

20 Peek GJ, Clemens F, Elbourne D, et al. CESAR: conventional ventilatory support $v s$ extracorporeal membrane oxygenation for severe adult respiratory failure. BMC Health Serv Res 2006; 6: 163.

21 Davidson WJ, Dorscheid D, Spragg R, et al. Exogenous pulmonary surfactant for the treatment of adult patients with acute respiratory distress syndrome: results of a meta-analysis. Crit Care 2006; 10: R41.

22 Cornet AD, Groeneveld AB, Hofstra JJ, et al. Recombinant human activated protein $\mathrm{C}$ in the treatment of acute respiratory distress syndrome: a randomized clinical trial. PLoS One 2014; 9: e90983.

23 Taylor RW, Zimmerman JL, Dellinger RP, et al. Low-dose inhaled nitric oxide in patients with acute lung injury: a randomized controlled trial. JAMA 2004; 291: 1603-1609.

24 Matthay MA, Brower RG, Carson S, et al. Randomized, placebo-controlled clinical trial of an aerosolized $\beta_{2}$-agonist for treatment of acute lung injury. Am J Respir Crit Care Med 2011; 184: 561-568.

25 Zeiher BG, Artigas A, Vincent JL, et al. Neutrophil elastase inhibition in acute lung injury: results of the STRIVE study. Crit Care Med 2004; 32: 1695-1702.

26 Boyle AJ, Mac Sweeney R, McAuley DF. Pharmacological treatments in ARDS: a state-of-the-art update. BMC Med 2013; 11: 166. 